\title{
Sanguinarine protects against osteoarthritis by suppressing the expression of catabolic proteases
}

\author{
Yan Ma1,2, Xuewu Sun ${ }^{1,2}$, Kangmao Huang ${ }^{1,2}$, Shuying Shen ${ }^{2}$, Xianfeng Lin $^{1,2}$, \\ Ziang Xie ${ }^{1,2}$, Jiying Wang ${ }^{2}$, Shunwu Fan ${ }^{1,2}$, Jianjun $\mathrm{Ma}^{1,2}$ and Xing Zhao ${ }^{1,2}$ \\ ${ }^{1}$ Department of Orthopaedic Surgery, Sir Run Run Shaw Hospital, Medical College of Zhejiang University, Hangzhou \\ 310016, China \\ ${ }^{2}$ Key Laboratory of Biotherapy of Zhejiang Province, Hangzhou 310016, China \\ Correspondence to: Xing Zhao, email: hsing78@gmail.com
}

Keywords: sanguinarine, chondrocyte, osteoarthritis, catabolic proteases

Received: February 10, $2017 \quad$ Accepted: March 24, $2017 \quad$ Published: April 11, 2017

Copyright: $\mathrm{Ma}$ et al. This is an open-access article distributed under the terms of the Creative Commons Attribution License 3.0 (CC BY 3.0), which permits unrestricted use, distribution, and reproduction in any medium, provided the original author and source are credited.

\section{ABSTRACT}

Inflammatory cytokines play critical roles in the pathogenesis of osteoarthritis. Recent studies have demonstrated that natural active substances can serve as alternative therapeutic agents for the prevention and treatment of osteoarthritis. Sanguinarine, an alkaloid isolated from the roots of Sanguinaria canadensis, is known to have anti-inflammatory properties. The aim of the present study was to investigate the therapeutic effect of Sanguinarine against osteoarthritis. Sanguinarine inhibited interleukin-1 $\beta$-induced expression of matrix metalloproteinase 1, 3, and 13, and A disintegrin and metalloproteinase with thrombospondin motifs- 5 in chondrocytes, which involved the nuclear factor-kB and $\mathrm{c}-J u n$ N-terminal kinase signalling pathways. Furthermore, the study of interleukin-1 $\beta$-induced cartilage matrix degradation in an anterior cruciate ligament transection-induced osteoarthritis model revealed that Sanguinarine ameliorated osteoarthritis by inhibiting the expression of matrix metalloproteinase 1, 3, and 13, and A disintegrin and metalloproteinase with thrombospondin motifs-5. In conclusion, we demonstrated for the first time that Sanguinarine suppressed the expression of matrix metalloproteinase 1, 3, and 13, and A disintegrin and metalloproteinase with thrombospondin motifs-5 in vitro, ex vivo, and in vivo, indicating its potential usefulness in treating osteoarthritis.

\section{INTRODUCTION}

Osteoarthritis $(\mathrm{OA})$ is a degenerative joint disease characterised by cartilage damage, subchondral bone remodelling and associated inflammation [1]. It is the most common form of arthritis and is accompanied by joint pain and stiffness, which can affect work and normal daily activities. Oral or topical nonsteroidal antiinflammatory drugs or tramadol can relieve OA symptoms [2]. However, joint replacement surgery is often the only effective treatment for terminal OA. Considering that few pharmacological therapies can delay OA development, new strategies for the treatment of OA are urgently needed.

Several studies have suggested that OA development is related to age, obesity, inflammation, trauma, and hereditary factors $[3,4]$, but the fundamental causes of OA remain unclear. Inflammatory cytokines such as interleukin (IL)-1 $\beta$ and tumour necrosis factor (TNF)- $\alpha$ have been reported to be involved in the development of OA [5]. Therefore, inhibition of inflammation may be effective in treating OA. However, newer biological therapies such as anti-TNF- $\alpha$ therapy are very expensive and could have numerous side effects [6]. Natural compounds have recently attracted increasing attention owing to their various bioactivities in human diseases. Several natural compounds including schisantherin A, thymoquinone, taraxasterol, sesamin, and astragalin have shown anti-OA properties [7-11], and our reach group has had a long-standing interest in the application of natural compounds [12-14]. 
Sanguinarine (SA), an alkaloid found in the roots of Sanguinaria canadensis, is approved by the U.S. Food and Drug Administration (FDA) [15]. It presents a wide range of biological activities including anti-inflammatory, antitumour, antimicrobial, anti-platelet, and antihypertensive effects, as well as inhibition of osteoclast formation [16-19]. Sanguinaria-containing toothpaste and oral rinse products have been used to reduce plaque and gingival inflammation [19].

In the present study, considering its widespread use and potential for suppressing inflammation, the therapeutic effect of SA against OA was investigated in vitro, ex vivo, and in vivo to determine its potential for future clinical applications.

\section{RESULTS}

\section{Catabolic protease expressionin human cartilage tissue}

First, the expression of catabolic proteases in human cartilage tissue was evaluated. Safranin Orange staining was used to assess the cartilage samples. Compared with the cartilage samples from patients with $\mathrm{OA}$, the cartilage tissue from healthy individuals contained more Safranin Orangepositive proteoglycan (Figure 1A). Second, the catabolic proteases were evaluated using immunohistochemistry. The results showed there were more catabolic proteases in the samples from patients with OA than in samples from patients without OA, based on the number of matrix metalloproteinase 1 (MMP1)-, MMP3-, MMP13-, and A disintegrin and metalloproteinase with thrombospondin motifs (ADAMTS)-5-positive cells (Figure 1B and 1C). The mRNA levels of MMP1, MMP3, MMP13, and ADAMTS-5 in the cartilage samples were consistent with the immunohistochemistry results (Figure 1D).

\section{Effects of SA on IL1- $\beta$-induced MMP1a, MMP3, MMP13, and ADAMTS-5 expression in chondrocytes}

Before investigating the effects of SA on IL1- $\beta$ induced MMP1a, MMP3, MMP13, and ADAMTS-5 expression in chondrocytes, the potential cytotoxicity of SA against chondrocytes was evaluated using the cell counting kit-8 (CCK-8) assay. The results showed that cell viability was not affected by SA at concentrations lower than 1.25 $\mu \mathrm{M}$ at both 24 and $48 \mathrm{~h}$ (Figure $2 \mathrm{~B}$ ). The calculated halfmaximal inhibitory concentration $\left(\mathrm{IC}_{50}\right)$ values for $\mathrm{SA}$ in chondrocytes at 24 and $48 \mathrm{~h}$ were 3.253 and $3.396 \mu \mathrm{M}$, respectively (Figure 2C). Therefore, 1.25 and $0.625 \mu \mathrm{M}$ were chosen as the high and low doses, respectively, for chondrocyte treatment. At these doses, SA had no effect on the expression of SRY-box 9 (Sox9), collagen type II $\alpha 1$ (COL2A1), and aggrecan in chondrocytes (Figure 2D). As shown in Figure 3A, the mRNA expression of MMP1a, MMP3, MMP13, and ADAMTS-5 increased following stimulation with IL-1 $\beta(10 \mathrm{ng} / \mathrm{mL})$. However, SA significantly decreased the expression of catabolic proteases in a dose-dependent manner. Similar changes were confirmed using western blot analysis, as shown in Figure $3 \mathrm{~B}$ and $3 \mathrm{C}$. Taken together, these results demonstrate that SA suppressed the expression of IL1- $\beta$-induced catabolic proteases in a dose-dependent manner.

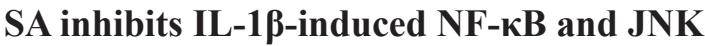 activation in chondrocytes}

To elucidate the mechanism by which SA stimulated IL-1 $\beta$-stimulated chondrocytes, we investigated the key signalling pathways such as those mediated by the mitogen-activated protein kinases (MAPKs), including extracellular signal-regulated kinase (ERK), p38, and Jun $\mathrm{N}$-terminal kinase (JNK), and the NF- $\mathrm{B}$ pathway, which are involved in the production of ADAMTSs and MMPs. As shown in Figure 4A, the MAPK and NF- $\kappa$ B pathways were clearly activated by IL-1 $\beta$. However, phosphorylation of JNK and NF- $\kappa \mathrm{B}$ decreased following treatment with $\mathrm{SA}$. These observations were confirmed using quantitative analysis (Figure 4B). In contrast, SA showed no obvious effect on ERK and P38 activation. These results indicate that SA inhibited IL-1 $\beta$-induced catabolic proteases, which involved the nuclear factor $(\mathrm{NF})-\kappa \mathrm{B}$ and c-Jun N-terminal kinase (JNK) signalling pathways.

\section{Effect of SA on IL-1及-induced cartilage matrix degradation ex vivo}

Considering that SA inhibited the IL-1 $\beta$-induced catabolic protease expression in vitro, we hypothesized that it could prevent IL-1 $\beta$-induced cartilage matrix degradation ex vivo. Therefore, mouse knee joint cartilage was placed in an explant culture medium and stimulated with IL-1 $\beta$ to induce matrix degradation. Samples were then randomly divided into four groups and treated with PBS, IL-1 $\beta$, and IL- $1 \beta$ with low or high concentration SA. The level of matrix degradation was evaluated using Safranin Orange staining. Compared to the IL-1 $\beta$-treated group, the cartilage of the group simultaneously treated with IL1- $\beta$ and SA exhibited more Safranin Orange-positive proteoglycan, which was dose-dependent (Figure 5A). We further investigated the expression of catabolic proteases in cartilage matrix using immunohistochemistry. Quantitative analysis demonstrated that SA significantly decreased the number of MMP1a-, MMP3-, MMP13-, and ADAMTS-5 positive cells (Figures $5 \mathrm{~A}$ and $6 \mathrm{~B}$ ). The ex vivo findings indicate that SA protected cartilage against degradation partly by inhibiting MMP1a, MMP3, MMP13, and ADAMTS-5.

\section{Effect of SA on anterior cruciate ligament transection (ACLT)-induced OA}

The preceding results demonstrated the effect of SA on chondrocytes in vitro and ex vivo. To determine whether $\mathrm{SA}$ delayed the progression of $\mathrm{OA}$ in vivo, low and high 
concentrations were administered intra-articularly to mice with anterior cruciate ligament transection (ACLT)induced OA. Six weeks after surgery, Safranin Orange staining was used to evaluate the degradation of the cartilage matrix. SA improved the cartilage surfaces of ACLT-induced OA mice in a dose-dependent manner (Figure 6A). Quantitative analysis using the Osteoarthritis Research Society International (OARSI) scoring indicated that even a low concentration of SA $(0.625 \mu \mathrm{M})$ yielded significantly lower OARSI scores than those reported for the OA group (Figure 6B). The mRNA expression levels of MMP1a, MMP3, MMP13, and ADAMTS-5 were evaluated in each group (Figure 6C). The OA group showed higher levels of MMP1a, MMP3, MMP13, and ADAMTS-5 expression than the sham surgery control group did. Furthermore, treatment with SA decreases all of the catabolic proteases investigated and the immunohistochemistry results were consistent with the mRNA data (Figure 7A and 7B). These results indicated that $\mathrm{SA}$ could inhibit OA progression in vivo.

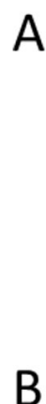

B
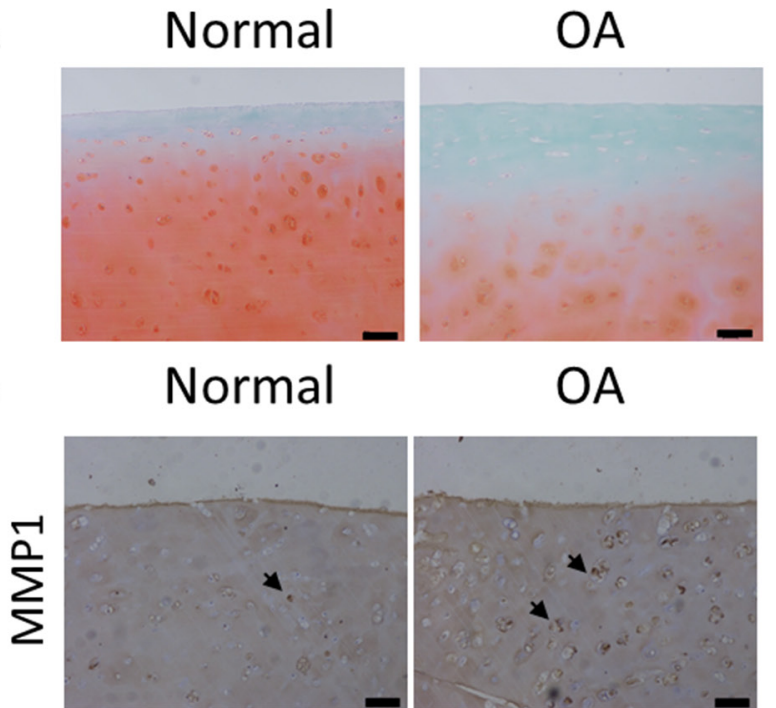

$\mathrm{OA}$
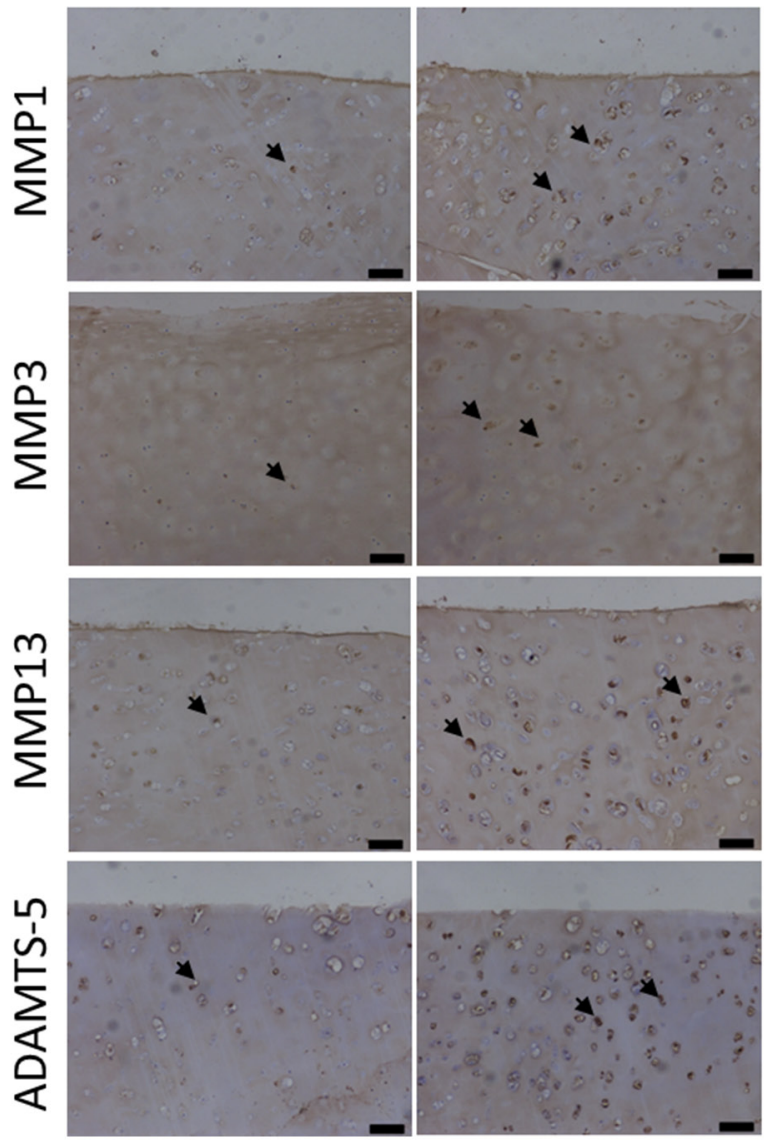
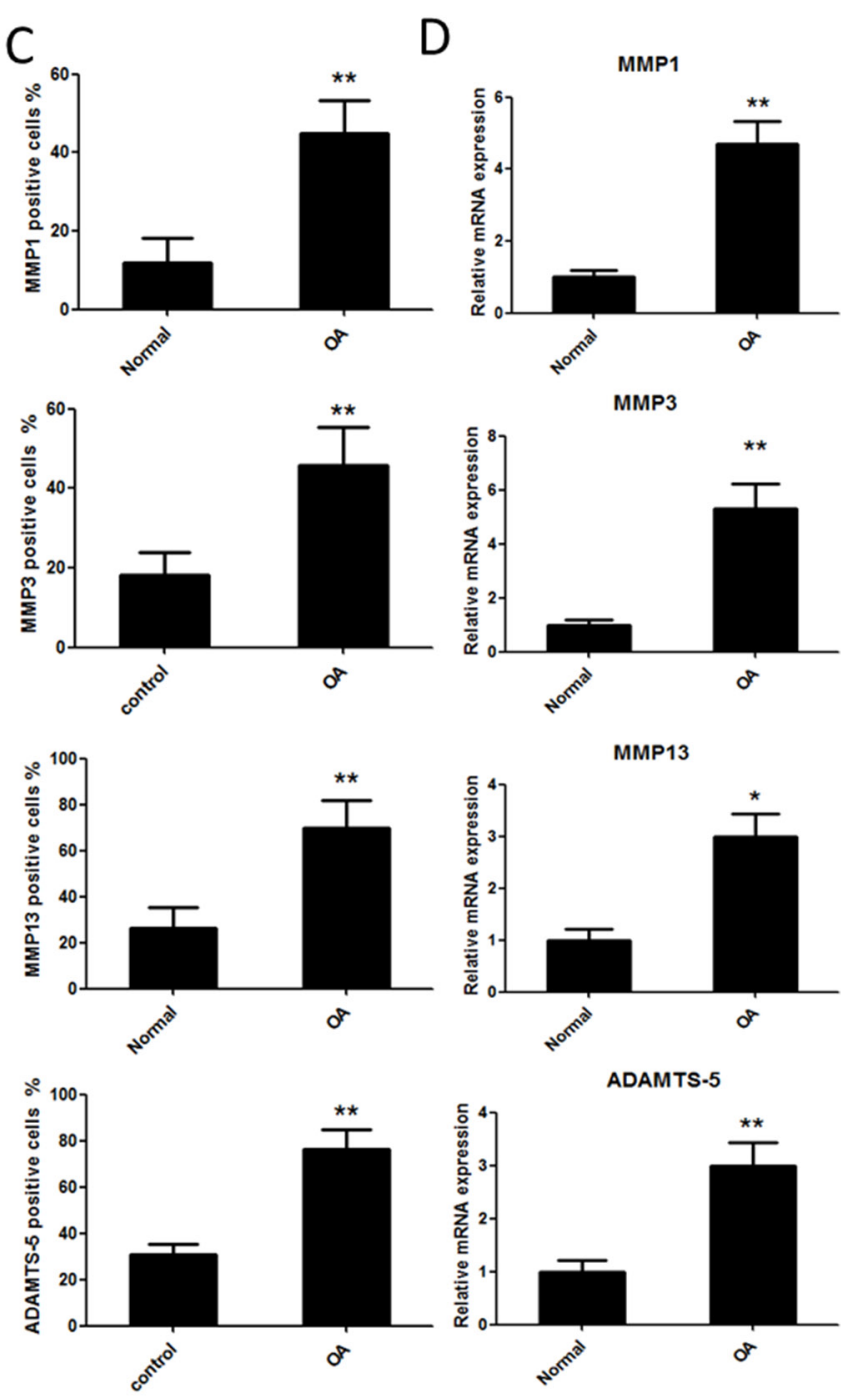

Figure 1: Safranin Orange staining and expression of catabolic proteases and extracellular matrix proteins in cartilage samples from human patients with or without osteoarthritis (OA). (A) Safranin Orange staining of cartilage samples from human patients with or without OA. Scale bar $=100 \mathrm{~mm}$. (B) Immunohistochemistry of matrix metalloproteinase (MMP)-1, MMP3, MMP13 and A disintegrin and metalloproteinase with thrombospondin motifs (ADAMTS)-5 in normal and OA human cartilage samples. Scale bar = $100 \mathrm{~mm}$. (C) Quantification of MMP1-, MMP3-, MMP13 and ADAMTS-5-positive cells in normal and OA human cartilage samples. (D) Relative mRNA expression of MMP1, MMP3, MMP13 and ADAMTS-5 in OA and normal human cartilage samples; $\mathrm{n}=6$, $* \mathrm{p}<0.05$ and $* * \mathrm{p}<0.01$ (Student's $t$-test). 
A<smiles>C[n+]1cc2c3c(ccc2c2ccc4cc5c(cc4c21)OCO5)OCO3</smiles>

B
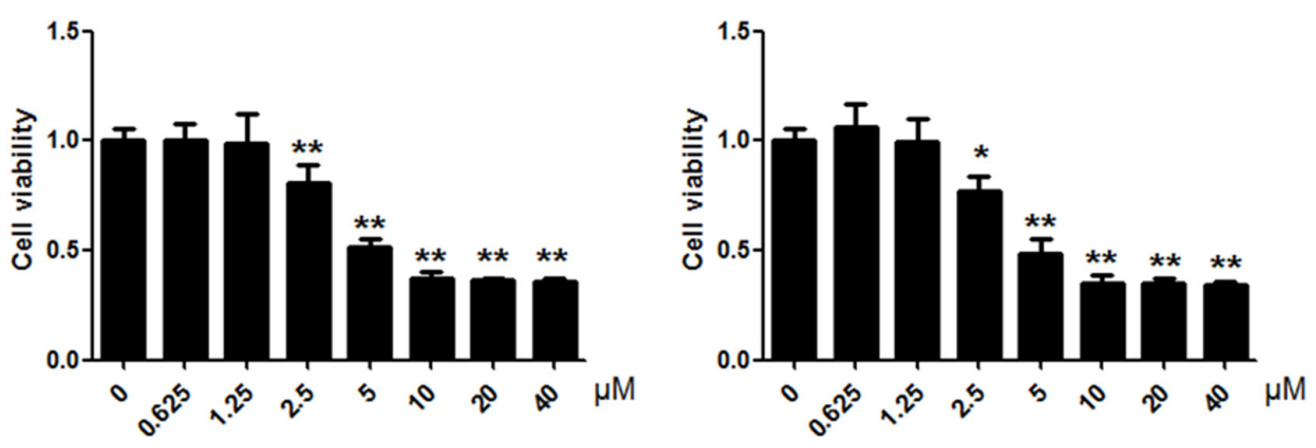

C

$24 \mathrm{~h}$

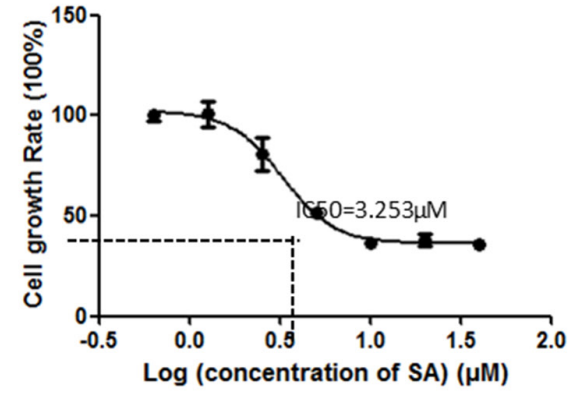

$48 \mathrm{~h}$

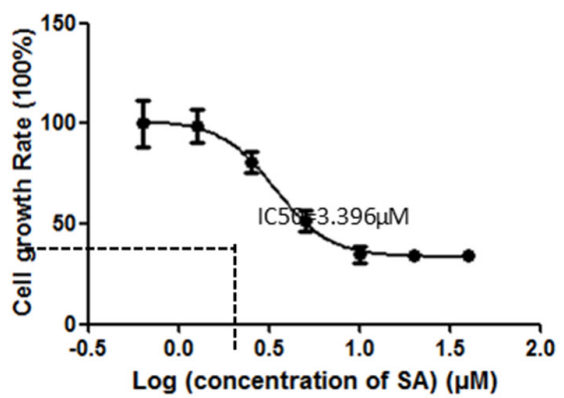

D
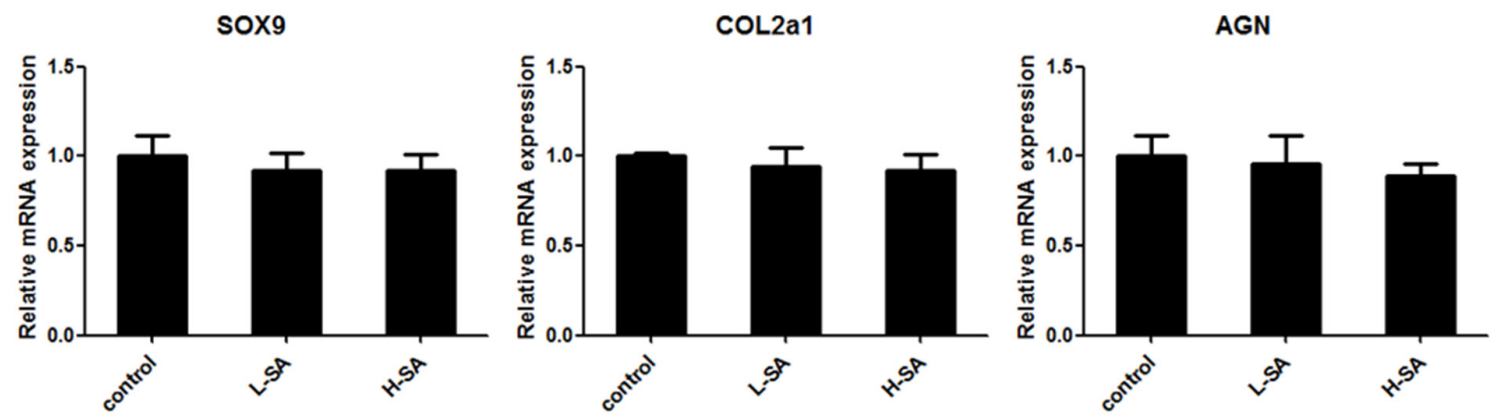

Figure 2: Effects of sanguinarine (SA) on viability of chondrocytes. (A) Chemical structural formula of SA. (B) Cells were cultured with $0-40 \mu \mathrm{M}$ SA for 24 or $48 \mathrm{~h}$, and viability was determined using a cell counting kit (CCK)-8 assay. (C) Calculated halfmaximal inhibitory concentration $\left(\mathrm{IC}_{50}\right)$ values of SA in chondrocytes for 24 or $48 \mathrm{~h}$ was 3.253 and $3.396 \mu \mathrm{M}$, respectively. (D) Cells were cultured with 1.25 or $0.625 \mu \mathrm{M} \mathrm{SA}$; subsequent expression of SRY-box 9 (SOX9), collagen type II $\alpha 1$ (COL2A1), and aggrecan were detected using quantitative real-time polymerase chain reaction (qPCR); $\mathrm{n}=6,{ }^{*} \mathrm{p}<0.05$ and $* * \mathrm{p}<0.01$ versus control (one-way analysis of variance, ANOVA). 
A
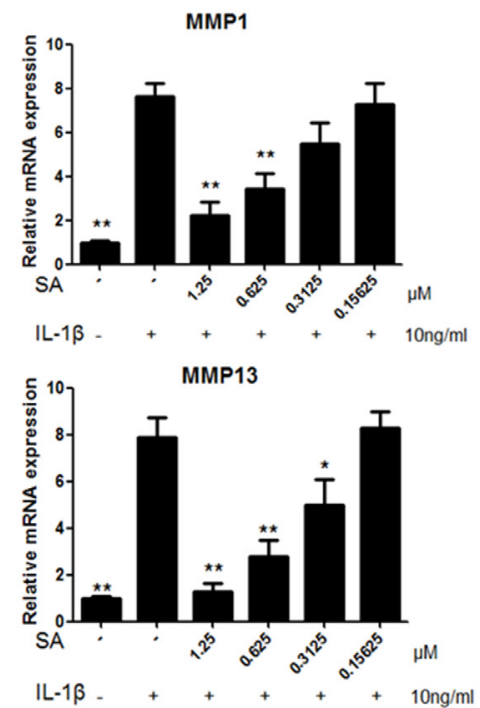
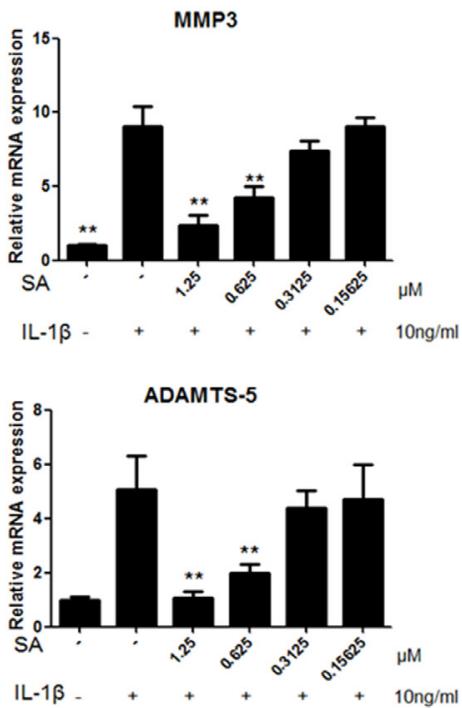

B IL- $\beta$

SA

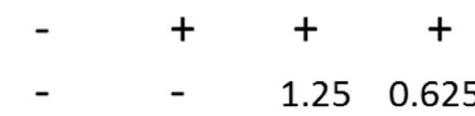

$1.25 \quad 0.625 \mu \mathrm{M}$

MMP1

MMP3

MMP13

ADAMTS-5

$\beta$-actin
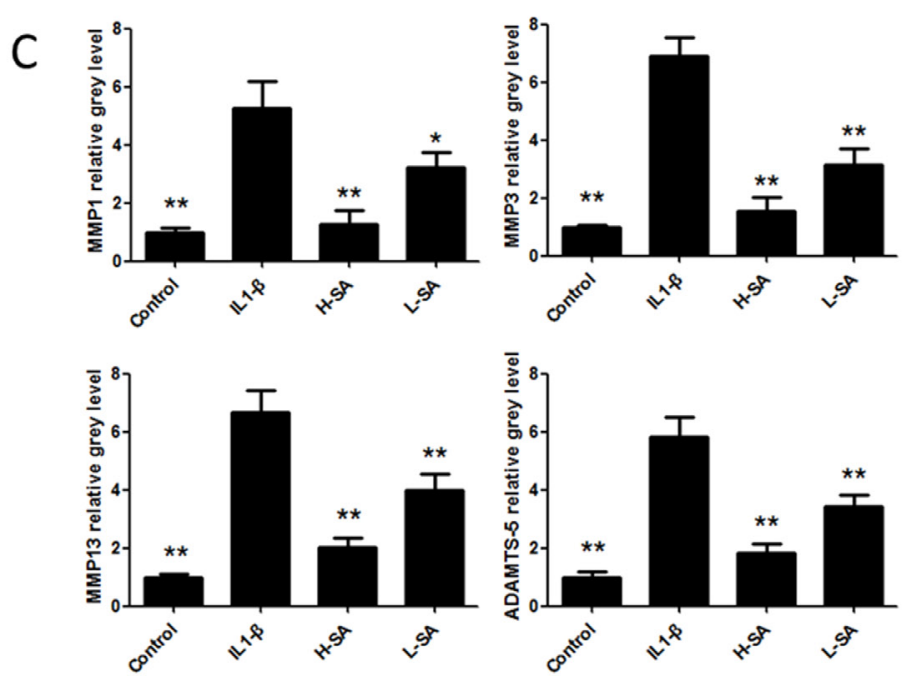

Figure 3: Sanguinarine (SA) inhibited interleukin (IL)-1ß-induced matrix metalloproteinase-1 (MMP1), MMP3, MMP13, and A disintegrin and metalloproteinase with thrombospondin motifs (ADAMTS)-5 expression in chondrocytes. (A) Effects of SA on mRNA expression of MMP1a, MMP3, MMP13, and ADAMTS-5 after treatment with IL-1 $\beta$ (10 $\mathrm{ng} / \mathrm{mL}$ ) for $24 \mathrm{~h}$. (B) Western blot analysis of MMP1a, MMP3, MMP13, and ADAMTS-5 protein expression levels after treatment with different doses of SA (with or without IL-1 $(10 \mathrm{ng} / \mathrm{mL})$ stimulation) for $48 \mathrm{~h}$. (C) Signal intensities of MMP1a, MMP3, MMP13, and ADAMTS- 5 were detected using ImageJ program; $n=6,{ }^{*} p<0.05$ and ${ }^{* *} \mathrm{p}<0.01$ versus IL-1 $\beta$-stimulated group (one-way analysis of variance, ANOVA). 


\section{DISCUSSION}

SA has a long history of use in the treatment of infections and as an analgesic, expectorant, sedative, and emetic [20]. Recently, the anti-inflammatory effects of SA were reported in animal models of acetic acid-induced colitis and lipopolysaccharide (LPS)-induced endotoxic shock [21, 22]. The present study showed, for the first time, that SA might be useful in treating OA.

Inflammatory cytokines are involved in the pathogenesis of OA. IL- $1 \beta$ is generated by inflamed synovium and invading leukocytes, and induces the release of MMPs and ADAMTS from both the synovium and cartilage $[5,23,24]$. This phenomenon is supported

A

IL-1 $\beta$

IL-1 $\beta+S A$

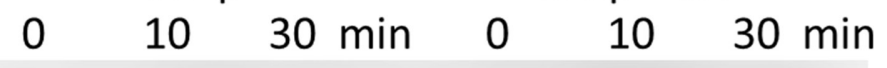

p-P38

P38

p-ERK

ERK

p-JNK

JNK

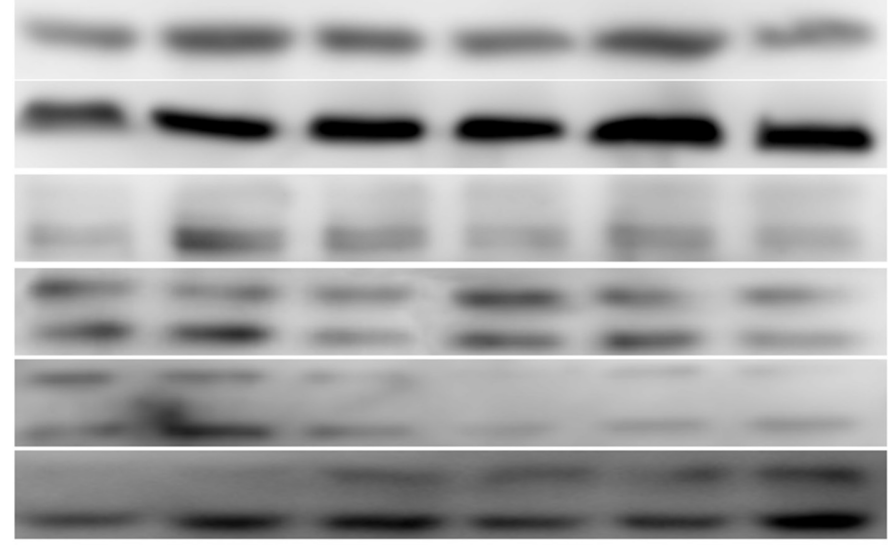

$p-\operatorname{lkB}-\alpha$

IKB- $\alpha$

$\beta$-actin

B
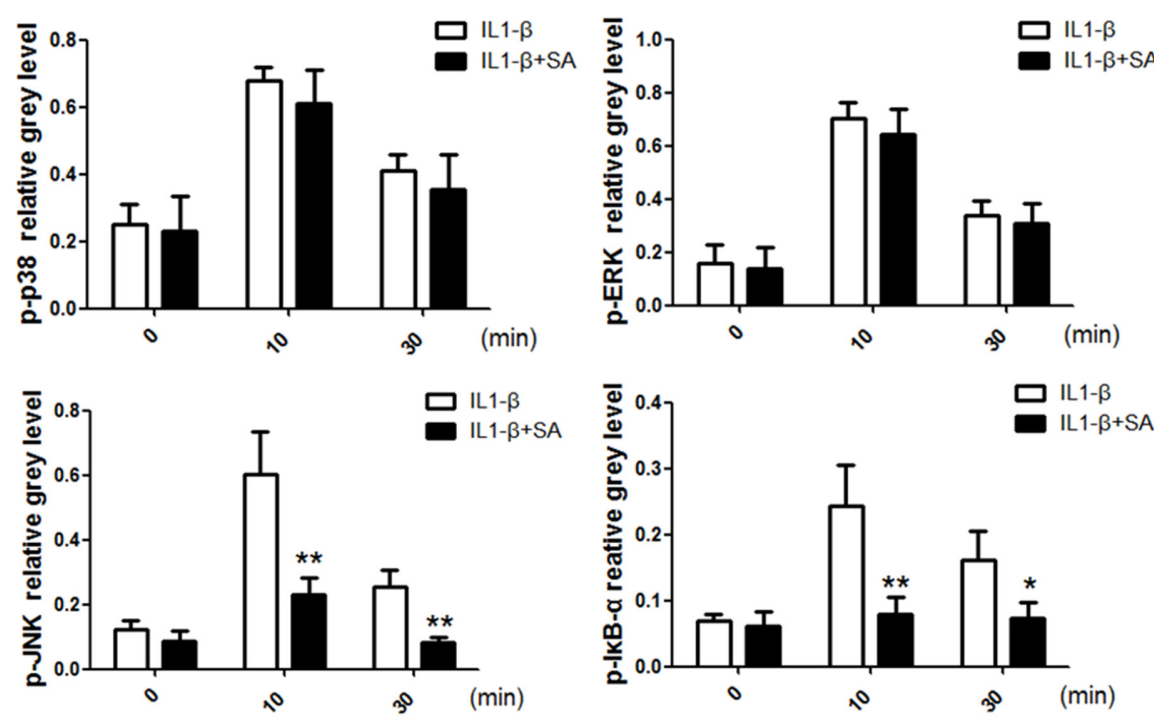

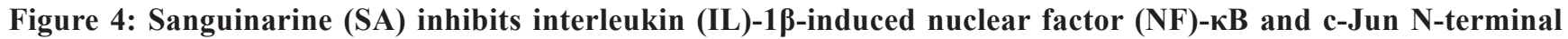
kinase (JNK) activation in chondrocytes. (A) Chondrocytes were treated with or without $1.25 \mu \mathrm{m} \mathrm{SA}$ for $4 \mathrm{~h}$ and then $10 \mathrm{ng} /$ mL IL-1 $\beta$ for indicated time. Phosphorylated (p)-p38, extracellular signal-regulated kinase (ERK), JNK, inhibitor of NF-Kb (I $\kappa B$ )- $\alpha$, total p38, ERK, JNK, IאB- $\alpha$, and $\beta$-actin were evaluated using western blot analysis. (B) Signal intensities of p-P38, ERK, JNK, and

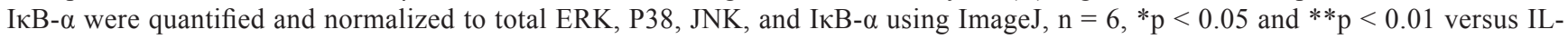
$1 \beta$-stimulated group (Student's $t$-test). 
by our results, which showed that the expression of MMP1, MMP3, MMP13, and ADAMTS-5 was higher in samples from patients with OA than in those from patients without OA (Figure 1A). ADAMTS and MMPs are catabolic proteases capable of degrading all types of extracellular matrix proteins, and the proteoglycan aggrecan and COL2 are the two major structural components of the cartilage extracellular matrix [25]. In particular, ADAMTS-5 is regarded as the main enzyme contributing to the degradation of aggrecan [26, 27].
Among the MMPs, MMP1, MMP3, and MMP13 are the main proteases involved in the degradation of COL2 $[28,29]$. Our results showed that SA decreased the expression of MMP1, MMP3, MMP13, and ADAMTS-5 in chondrocytes.

ERK, JNK, and the NF- $\mathrm{KB}$ signalling pathways are well-known to be involved in the pathogenesis of $\mathrm{OA}[30,31]$. NF- $\mathrm{KB}$ and JNK signalling are the major upstream mediators of the expression of catabolic factors [32]. It has been shown that aggrecan degradation is

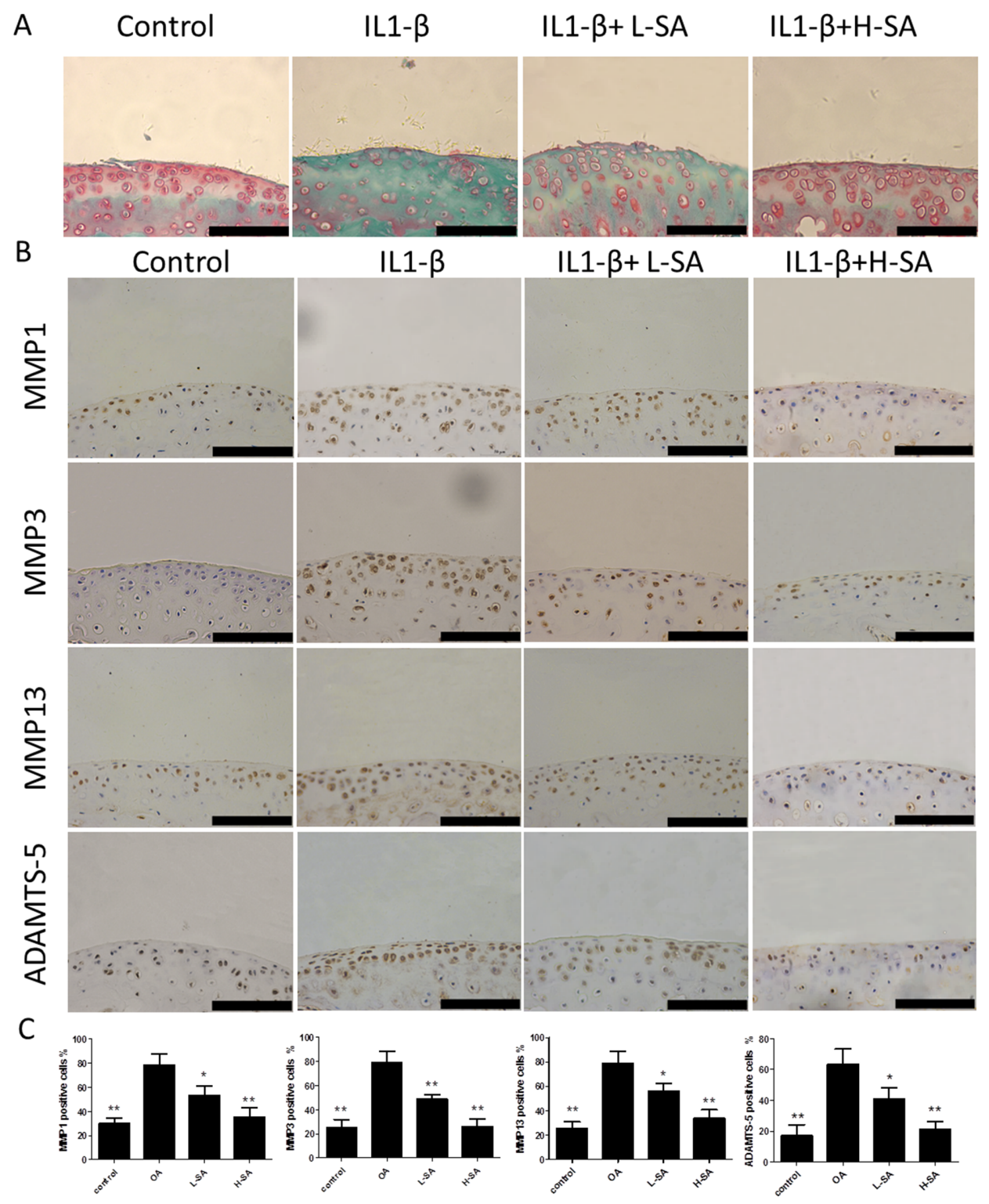

Figure 5: Effect of sanguinarine (SA) on interleukin (IL)-1ß-induced cartilage matrix degradation ex vivo. (A) Safranin Orange staining of ex vivo cartilage samples. Scale bar $=100 \mathrm{~mm}$. (B) Immunohistochemistry was performed to assess expression of matrix metalloproteinase (MMP)-1a, MMP3, MMP13, and A disintegrin and metalloproteinase with thrombospondin motifs (ADAMTS)-5 in different samples. Scale bar $=100 \mathrm{~mm}$. (C) Quantification of MMP1a-, MMP3-, MMP13-, and ADAMTS-5-positive cells in different samples. Scales bar $=100 \mathrm{~mm} ; \mathrm{n}=6,{ }^{*} \mathrm{p}<0.05$ and $* * \mathrm{p}<0.01$ versus IL-1 $\beta$-stimulated group (one-way ANOVA). Control, dimethyl sulphoxide (DMSO); IL-1 $\beta, 10$ ng/mL; L-SA, 10 ng/mL IL-1 $\beta+0.625 \mu \mathrm{M}$ SA; H-SA, 10 ng/mL IL- $1 \beta+1.25 \mu$ M SA. 
mainly regulated by the JNK2 pathway [33]. Previous studies have demonstrated that the inhibition of MAPK and NF- $\kappa \mathrm{B}$ activity reduces the production of inflammatory mediators in chondrocytes [8, 10]. In concurrence with these studies, we found that SA suppressed IL1- $\beta$-induced NF- $\kappa \mathrm{B}$ and JNK activation, which presented a high level of specificity in repressing the production of catabolic factors. This finding is partially supported by the results of Chaturvedi et al. [34] that SA is a potent suppressor of $N F-\kappa B$ activation In addition, Niu et al. [35] found that SA inhibited the phosphorylation of p38 and ERK, which altered the synthesis and release of inflammatory mediators in peritoneal macrophages. In contrast, SA had no influence on p38 and ERK in our study. This is because the study by Niu et al. [35] investigated the effects of SA

\section{A}
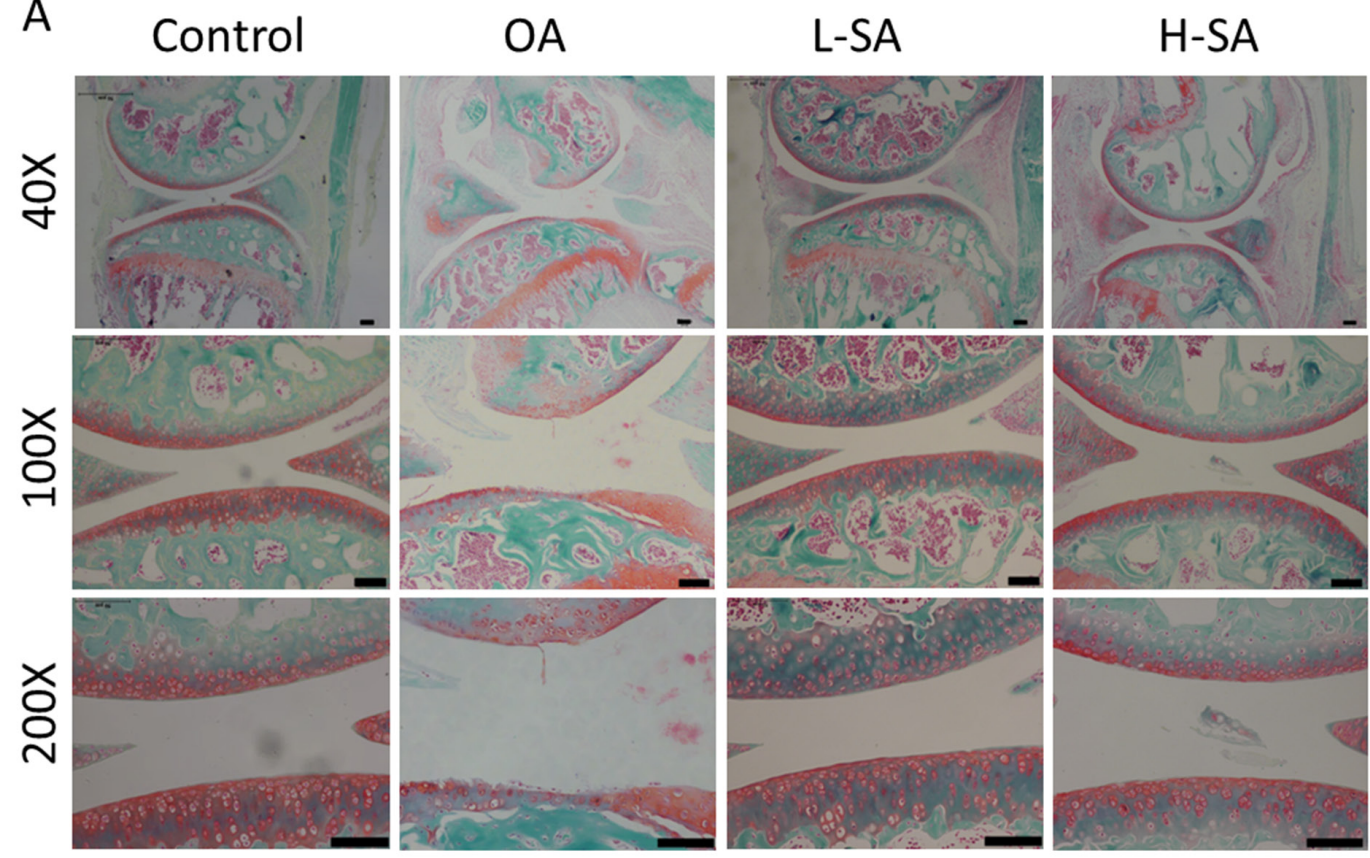

B

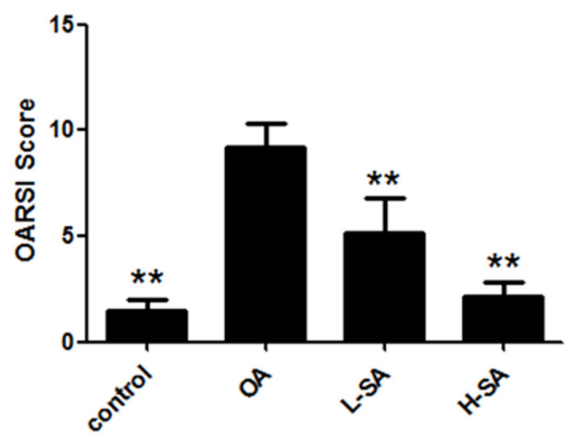

C
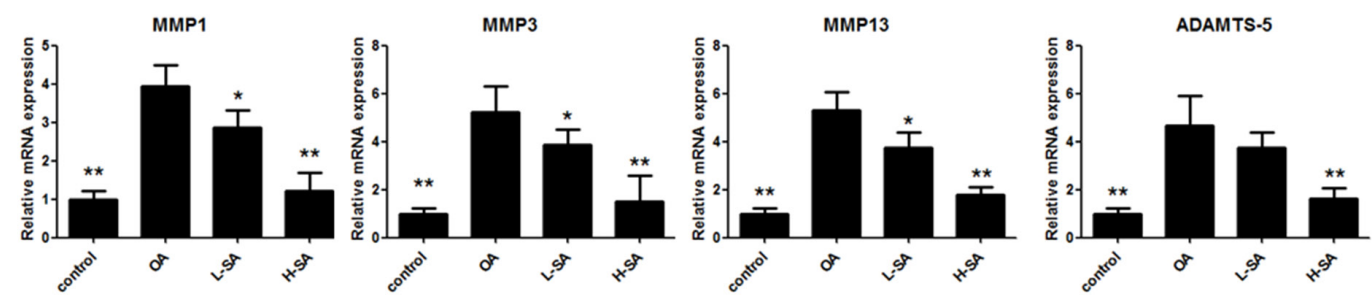

Figure 6: Effect of sanguinarine (SA) on anterior cruciate ligament transection (ACLT)-induced osteoarthritis (OA). (A) Safranin Orange staining of cartilage samples 6 weeks after OA induction. Scale bar $=100 \mathrm{~mm}$. (B) OARSI score of samples 6 weeks after OA induction. (C) mRNA expression of matrix metalloproteinase (MMP)-1a, MMP3, MMP13 and A disintegrin and metalloproteinase with thrombospondin motifs (ADAMTS)-5 in different groups; $n=6, * p<0.05$ and $* * p<0.01$ versus OA group (one-way analysis of variance, ANOVA). Control, sham group; OA, ACLT-induced OA group; L-SA, ACLT-induced OA treated with $0.625 \mu \mathrm{M}$ intra-articularly administered SA twice a week; H-SA, ACLT-induced OA treated with $1.25 \mu \mathrm{M}$ intra-articularly administered SA twice a week. 
using peritoneal macrophages, while we demonstrated the SA-induced inhibition of IL1- $\beta$-induced NF- $\kappa$ B and JNK activation in chondrocytes.

There is considerable scope for further investigation of the effects of SA against OA. First, we investigated the effects of SA on chondrocytes alone. The remodelling of subchondral bone and the associated inflammation in the synovium are typical pathological features of OA, and recent studies have shown that SA inhibited the formation of osteoclasts. Therefore, an investigation focusing on the subchondral bone and synovium would be required to completely elucidate the role of SA in OA. Furthermore, decreasing the frequency of intra-articular treatment administration with a more practical delivery system will be valuable for potential clinical applications. In conclusion, our study showed that SA suppressed the expression of catabolic proteases in vitro, ex vivo, and in vivo, indicating its potential value in the treatment of OA.

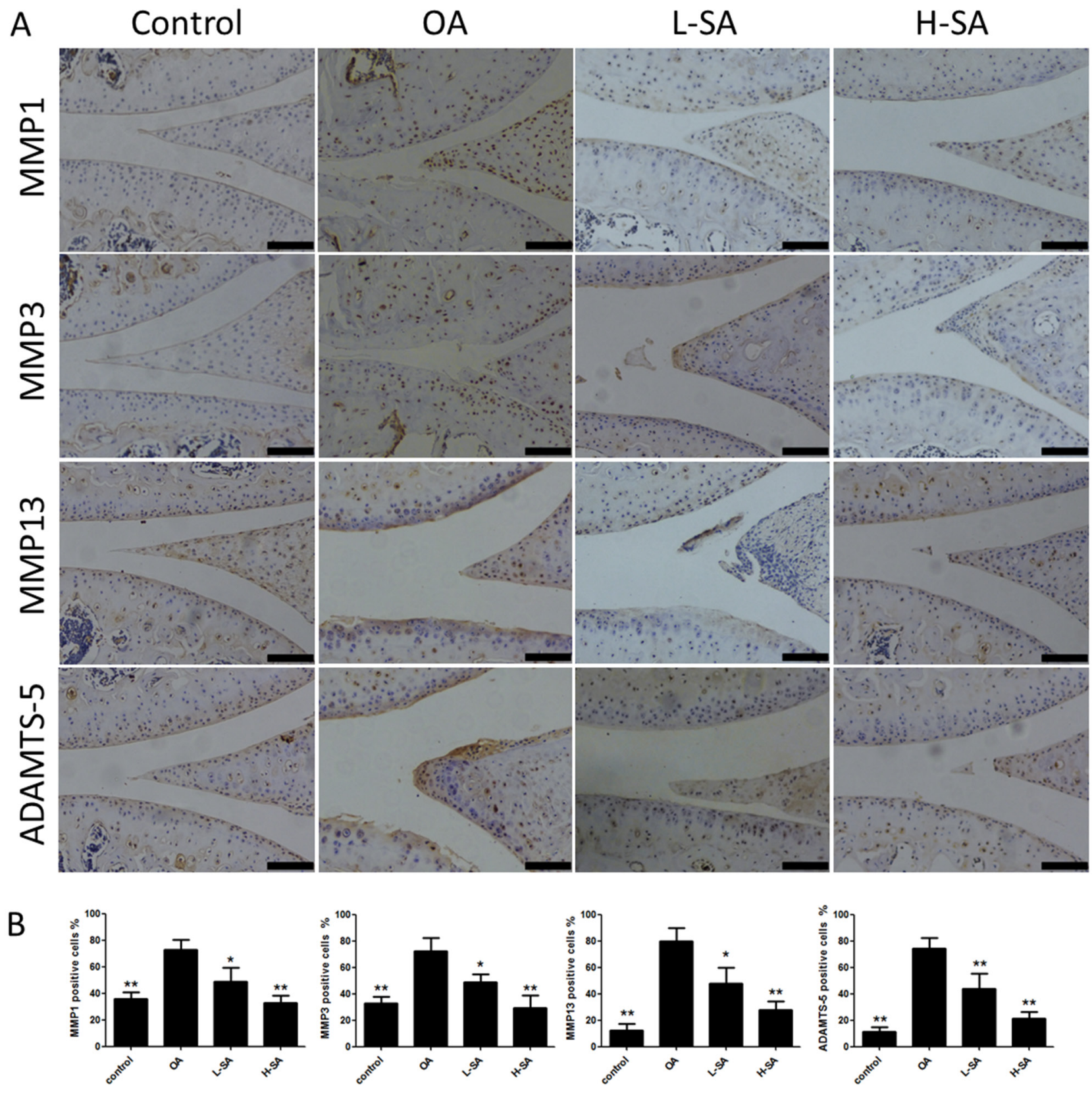

Figure 7: Effect of sanguinarine (SA) on cartilage matrix degradation in vivo. (A) Immunohistochemistry of matrix metalloproteinase (MMP)-1a, MMP3, MMP13, and A disintegrin and metalloproteinase with thrombospondin motifs (ADAMTS)-5 in cartilage samples 6 weeks after surgery. Scale bar $=100 \mathrm{~mm}$. (B) Quantification of MMP1a-, MMP3-, MMP13-, and ADAMTS-5-positivecells in cartilage samples 6 weeks after surgery; $\mathrm{n}=6,{ }^{*} \mathrm{p}<0.05$ and $* * \mathrm{p}<0.01$ versus osteoarthritis (OA) group (one-way analysis of variance, ANOVA). 
Table 1: Polymerase chain reaction (PCR) primers

\begin{tabular}{|c|c|c|c|}
\hline Gene & Strand & Primer sequences & Origin \\
\hline \multirow[t]{2}{*}{ GAPDH } & forward & 5'-AGGGCCCTGACAACTCTTTT-3' & human \\
\hline & reverse & 5'-AGGGGTCTACATGGCAACTG-3' & \\
\hline \multirow[t]{2}{*}{$M M P 1$} & forward & 5'-CAAGTGCTGTGGCACTGTTT-3' & human \\
\hline & reverse & 5'-ACTTGTCCCAGCATTGAACC-3' & \\
\hline \multirow[t]{2}{*}{$M M P 3$} & forward & 5'-CTGGGAAAATCAGCCATTGT-3' & human \\
\hline & reverse & 5'-AGGTTCTGGAGGGACAGGTT-3' & \\
\hline \multirow[t]{2}{*}{ MMP13 } & forward & 5'-AACATCCAAAAACGCCAGAC-3' & human \\
\hline & reverse & 5'-TTGGCAATATGCAGAAGCAG-3' & \\
\hline \multirow[t]{2}{*}{ ADAMTS-5 } & forward & 5'-TAGGCGTCTTTGGCTTCAGT-3' & human \\
\hline & reverse & 5'-GCTTTCAGGCTGACCAGTTC-3' & \\
\hline \multirow[t]{2}{*}{ Col2A1 } & forward & 5'-CAACCAGACCGTGCTTTTCA-3' & human \\
\hline & Reverse & 5'-CAACCGTAGCAATCGACCAG-3' & \\
\hline \multirow[t]{2}{*}{ Aggrecan } & forward & 5'-TCCCCGTAGAAGAGGAGACA-3' & human \\
\hline & reverse & 5'-AAGACAGGGGTATGCAGCTT-3' & \\
\hline \multirow[t]{2}{*}{ GAPDH } & forward & 5'-ACCCAGAAGACTGTGGATGG-3' & mouse \\
\hline & reverse & 5'-CACATTGGGGGTAGGAACAC-3' & \\
\hline \multirow[t]{2}{*}{ MMPla } & forward & 5'-CTAAGGCAGGAGGATTGCTG-3' & mouse \\
\hline & reverse & 5'-TGCGAAGGGCTTAGTGTCTT-3' & \\
\hline \multirow[t]{2}{*}{$M M P 3$} & forward & 5'-CTCAGAGGAGCAAGGGTTTG-3' & mouse \\
\hline & reverse & 5'-CAACTGCGAAGATCCACTGA-3' & \\
\hline \multirow[t]{2}{*}{ MMP13 } & forward & 5'-GAGCCACAGATGAGCACAGA-3' & mouse \\
\hline & reverse & 5'-ATGTAAGGCCACCTCCACTG-3' & \\
\hline \multirow[t]{2}{*}{$A D A M T S-5$} & forward & 5'-CAAGTTAGCTGGCTGGGAAG-3' & mouse \\
\hline & reverse & 5'-TCCAGATGCAGCAAACAAAG-3' & \\
\hline \multirow[t]{2}{*}{ Sox 9} & forward & 5'-AGAAAGGAGTGAGGGGGTGT-3' & mouse \\
\hline & reverse & 5'-TGCCGGTTCTCAGTAGCTTT-3' & \\
\hline \multirow[t]{2}{*}{ Col2A1 } & forward & 5'-CTGGGCCACAGGTGAGTATT-3' & mouse \\
\hline & reverse & 5'-CCAGGATACCAACTGCCTGT-3' & \\
\hline \multirow[t]{2}{*}{ Aggrecan } & forward & 5'-AAGGACGAGTTCCCTGGAGT-3' & mouse \\
\hline & reverse & 5'-CTGGGGATGTCGCATAAAAG-3' & \\
\hline
\end{tabular}

\section{MATERIALS AND METHODS}

\section{Chemicals and reagents}

SA and dimethyl sulphoxide (DMSO) were purchased from Sigma-Aldrich (St Louis, MO, USA). Dulbecco's modified Eagle's medium (DMEM), foetal bovine serum (FBS), and penicillin/streptomycin were purchased from Gibco-BRL (Gaithersburg, MD, USA).
The CCK-8 was obtained from Dojindo Molecular Technology (Kumamoto, Japan). SA was dissolved in DMSO and stored at $-20^{\circ} \mathrm{C}$. The experiments were carried out in the absence of visible light to prevent photosensitivity. SA was diluted with cell culture medium to obtain a final DMSO concentration $<0.1 \%$ of the total volume. The following antibodies against ERK (sc292838), c-Jun N-terminal kinase (JNK, sc-572), p38 (sc535), phospho-ERK (Thr202/Tyr204, sc-16981), phospho- 
JNK (Thr183/Tyr185, sc-6254), phospho-p38 (Thr180/ Tyr182, sc-17852), MMP3 (sc6839), MMP-13 (sc30073), ADAMTS-5 (sc83186), aggrecan (sc25674), and $\beta$-actin (sc25674) were from Santa Cruz (Santa Cruz, CA, USA).

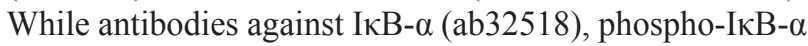
(ab133462), MMP1 (ab137332), and Col2A1 (ab34712) were purchased from Abcam (Cambridge, UK). All other reagents were purchased from Sigma-Aldrich (St Louis, MO, USA) unless stated otherwise.

\section{Human cartilage}

Human cartilage samples were collected according to protocols approved by the Ethics Committee of Sir Run Run Shaw Hospital and the methods were carried out in accordance with the approved guidelines. Written informed consent was obtained from all subjects. Six control (healthy) cartilages were harvested from human cadavers without a history of OA while six pathological cartilages were acquired from patients with end-stage symptomatic knee OA at the time of surgery for total knee replacement. The human cartilage samples were graded based on the modified 5-point Collins scale. In the OA group, all the samples were classified as grade 3 while those in the control group were all grade 0 . Human cartilage samples were obtained using previously described methods [13].

\section{Cell culture}

Primary articular cartilage was isolated from the femoral condyles and tibial plateaus of $\mathrm{C} 57 \mathrm{~B} / 6$ mice on postnatal day 5-6, according to a previous study [36]. Chondrocytes were cultured in DMEM containing $10 \%$ (v/v) FBS, $100 \mathrm{U} / \mathrm{mL}$ penicillin, and $100 \mu \mathrm{g} / \mathrm{mL}$ streptomycin at $37^{\circ} \mathrm{C}$ with $5 \% \mathrm{CO}_{2}$. Third-passage cartilage cells were used in all of the experiments.

\section{Cell viability assay}

The cytotoxic effects of SA were assessed using CCK-8 assays. Chondrocytes were seeded in 96-well plates at a density of $8 \times 10^{3}$ cells/well in triplicate and cultured in complete DMEM for $24 \mathrm{~h}$. The cells were treated with different concentrations of SA $(0,0.15625$, $0.3125,0.625,1.25,2.5,5,10,20$, or $40 \mu \mathrm{M}$ ) for 24 or $48 \mathrm{~h}, 10 \mu \mathrm{L}$ CCK- 8 buffer was added to each well, and then the cells were incubated at $37^{\circ} \mathrm{C}$ for $2 \mathrm{~h}$. This was followed by measurement of the absorbance at $450 \mathrm{~nm}$ (650 nm reference) using an ELX800 absorbance reader (Bio-Tek, Winooski, VT, USA). The cell viability was calculated relative to that of the control cells from the optical density (OD) data using the following formula: cell viability $=($ experimental group OD - zeroing OD $) /$ (control group OD - zeroing OD). The experiments were performed six times, and the significance was determined as indicated in the figure legend.

\section{Quantitative real-time polymerase chain reaction (qPCR)}

Total RNA was extracted from chondrocytes or cartilage samples using the TRIzol reagent (Invitrogen Inc., Carlsbad, CA, USA) according to the manufacturer's instructions. cDNA was synthesized from $1 \mu \mathrm{g}$ total RNA using reverse transcriptase (TaKaRa Biotechnology, Otsu, Japan). The real-time polymerase chain reaction (PCR) was performed using the SYBR Premix Ex Taq kit (TaKaRa, Biotechnology, Otsu, Japan) and an ABI 7500 sequencing detection system (Applied Biosystems, Foster City, CA, USA). The following cycling conditions were used: 40 cycles of denaturation at $95^{\circ} \mathrm{C}$ for $5 \mathrm{~s}$ and amplification at $60^{\circ} \mathrm{C}$ for $24 \mathrm{~s}$. The relative level of expression of each target gene was calculated using the $2^{-\Delta \Delta c_{\mathrm{T}}}$ method. Each real-time PCR included six different experimental samples. The data were represented as target gene expression normalized to the reference gene. Error bars indicate the SD of the mean of replicates. All pairs of primer sequences were designed using the primer 5.0 software and are listed in Table 1.

\section{Western blot analysis}

To investigate the effect of SA on the IL1- $\beta$-induced expression of MMP1, MMP3, MMP13, and ADAMTS-5, chondrocytes were seeded in six-well plates at a density of $5 \times 10^{5}$ cells/well. When the cells were confluent, they were treated with SA with and without IL-1 $(10 \mathrm{ng} / \mathrm{mL})$ stimulation, for $48 \mathrm{~h}$. Then, total protein was extracted from cultured cells using radio-immunoprecipitation assay (RIPA) lysis buffer (Sigma-Aldrich, St Louis, MO, USA) containing $50 \mathrm{mM}$ Tris-hydrochloride $(\mathrm{HCl}), 150 \mathrm{mM}$ sodium chloride $(\mathrm{NaCl}), 5 \mathrm{mM}$ ethylenediaminetetraacetic acid (EDTA), 1\% Triton X-100, $1 \mathrm{mM}$ sodium fluoride, 1 $\mathrm{mM}$ sodium vanadate, $1 \%$ deoxycholate, and a protease inhibitor cocktail. Lysates were centrifuged at $12,000 \times \mathrm{g}$ for $15 \mathrm{~min}$, and the supernatants that contained the proteins were collected.

To examine the target signalling pathway of SA, chondrocytes were seeded in six-well plates at a density of $5 \times 10^{5}$ cells/well. When the cells were confluent, they were either untreated or pre-treated with $1.25 \mu \mathrm{M} \mathrm{SA}$ for 4 $h$. The cells were then stimulated with $10 \mathrm{ng} / \mathrm{mL}$ IL $1-\beta$ for 0,10 , and $30 \mathrm{~min}$, followed by the collection of the total protein as above.

Protein concentrations were determined using the bicinchoninic acid (BCA, Thermo Fisher, Waltham, MA, USA) assay. Then, $30 \mu \mathrm{g}$ of each protein lysate was resolved using $10 \%$ sodium dodecyl sulphatepolyacrylamide gel electrophoresis (SDS-PAGE, SigmaAldrich, St Louis, MO, USA) and then transferred to polyvinylidene difluoride membranes (Millipore, Bedford, MA, USA). Then, the membranes were blocked with 5\% skimmed milk in Tris-buffered saline plus Tween (TBST, 
0.05 M Tris/0.15 M NaCl [pH 7.5] and 0.2\% Tween-20; Invitrogen, San Diego, CA, USA) for $1 \mathrm{~h}$, and then incubated with primary antibodies diluted in $1 \%(\mathrm{w} / \mathrm{v})$ skimmed milk in TBST overnight at $4^{\circ} \mathrm{C}$. The membranes were then washed and incubated with the appropriate secondary antibodies conjugated with IRDye $800 \mathrm{CW}$ (molecular weight: $1162 \mathrm{Da}$ ). The antibody reactivity was detected via exposure in an Odyssey infrared imaging system (LI-COR, Inc., Lincoln, NE, USA). Quantitative analysis of the band intensity was carried out using the ImageJ software.

\section{Cartilage explant cultures}

The animal experiments in this study were performed in accordance with the principles and procedures of the National Institutes of Health (NIH) Guide for the Care and Use of Laboratory Animals and the guidelines for animal treatment of Sir Run Run Shaw Hospital. All experimental protocols in this study were approved by the Ethics Committee of Sir Run Run Shaw Hospital. Femoral condyle cartilage was obtained from 12-week-old C57BL/6 mice without the bone, periosteum, or synovium and cultured in DMEM containing 10\% FBS (v/v), antibiotics, and $2 \mathrm{mM}$ L-glutamine (Invitrogen) in $5 \% \mathrm{CO}_{2}$ at $37^{\circ} \mathrm{C}$. After 2 days of culturing, the explants were washed with serum-free medium and dispensed into tissue-culture dishes with serum-free medium containing $10 \mathrm{ng} / \mathrm{mL}$ IL1- $\beta$ with or without 0.625 or $1.25 \mu \mathrm{M} \mathrm{SA}$. Furthermore, there were six explants in each group, and after a 72-h incubation, the samples were removed from the culture wells and fixed in 10\% formalin.

\section{ACLT surgery-induced OA and intra-articular delivery of SA}

Twenty-four 8-week-old male C57BL/6 mice were divided into four groups and those in group I underwent a sham knee surgery. The mice in the other three groups were subjected to ACLT surgery of the knees, as previously described [37]. Then, 10 days later, intra-articular injections of normal saline (group II), lowand high-dose SA (0.625 and $1.25 \mu \mathrm{M}$, groups III and IV, respectively) were administered to the mice twice a week. Six weeks later, the distal femur of each mouse was dissected, embedded in paraffin, and examined using Safranin Orange and immunostaining.

\section{Histological analysis and immunohistochemistry of murine knee joints}

The knee joints were examine using histological and immunohistochemical assays. We used 4\% (v/v) neutral buffered formalin to fix the tissue samples for $24 \mathrm{~h}$ and neutral 10\% EDTA solution to decalcify for 1 month at room temperature. Next, the samples were dehydrated in a graded series of ethanol solutions, embedded in paraffin blocks, and sagittal serial sections were cut from across the entire knee joint. Six $8-\mu \mathrm{m}$ histological sections from different depths of each joint were cut at five-slide intervals, stained with Safranin O-fast green, and then the OARSI histopathology grading and staging system was used to grade the tissue degeneration [38]. Five sequential sections per joint from each group were immunostained. The sections were incubated at $4^{\circ} \mathrm{C}$ with antibodies against MMP1, MMP3, MMP13, and ADAMTS-5 overnight, and then incubated for $2 \mathrm{~h}$ at room temperature with the secondary antibodies (Beyotime Institute of Biotechnology Inc., Jiangsu, China). The number of positively stained cells on the entire articular surface (including the femoral condyle and tibial plateau area) per specimen was counted and the percentage positive cells was calculated [12].

\section{Statistical analysis}

All data are presented as the mean \pm standard deviation (SD). The statistical data were analysed using a one-way analysis of variance (ANOVA)/Tukey's post-hoc test or Student's $t$-tests. A $* \mathrm{p}<0.05$ or $* * \mathrm{p}<0.01$ was considered statistically significant.

\section{ACKNOWLEDGMENTS}

This study was sponsored by grants from the National Nature Science Fund of China (81171739, 81101378, $81271971,81271972,81601925$ and 31270997), the Natural Science Fund of Zhejiang Province (Y2110372), funds of the Science and Technology Department of Zhejiang Province (2009C03014-1), and the Zhejiang Provincial Program for the cultivation of high-level innovative health talents. Medical Science and Technology Project of Zhejiang Province (2017179447).

\section{CONFLICTS OF INTEREST}

All authors declare that they have no conflicts of interest.

\section{REFERENCES}

1. UK NCGC. Osteoarthritis: Care and Management in Adults. (London: National Institute for Health and Care Excellence), 2014.

2. Hauk L. Treatment of knee osteoarthritis: a clinical practice guideline from the AAOS. Am Fam Physician. 2014; 89:918-920.

3. Haq SA, Davatchi F, Dahaghin S, Islam N, Ghose A, Darmawan J, Chopra A, Yu ZQ, Dans LF, Rasker JJ. Development of a questionnaire for identification of the risk factors for osteoarthritis of the knees in developing countries. A pilot study in Iran and Bangladesh. An 
ILAR-COPCORD phase III study. Int J Rheum Dis. 2010; 13:203-214.

4. Dahaghin S, Tehrani-Banihashemi SA, Faezi ST, Jamshidi AR, Davatchi F. Squatting, sitting on the floor, or cycling: are life-long daily activities risk factors for clinical knee osteoarthritis? Stage III results of a community-based study. Arthritis Rheum. 2009; 61:1337-1342.

5. Kapoor M, Martel-Pelletier J, Lajeunesse D, Pelletier JP, Fahmi H. Role of proinflammatory cytokines in the pathophysiology of osteoarthritis. Nat Rev Rheumatol. 2011; 7:33-42.

6. Conaghan PG. Osteoarthritis in 2012: parallel evolution of OA phenotypes and therapies. Nat Rev Rheumatol. 2013; 9:68-70.

7. Liao S, Zhou K, Li D, Xie X, Jun F, Wang J. Schisantherin A suppresses interleukin-1beta-induced inflammation in human chondrocytes via inhibition of NF-kappaB and MAPKs activation. Eur J Pharmacol. 2016; 780:65-70.

8. Wang D, Qiao J, Zhao X, Chen T, Guan D. Thymoquinone inhibits IL-1 $\beta$-induced inflammation in human osteoarthritis chondrocytes by suppressing NF- $\kappa \mathrm{B}$ and MAPKs signaling pathway. Inflammation. 2015; 38:2235-2241.

9. Piao T, Ma Z, Li X, Liu J. Taraxasterol inhibits IL-1betainduced inflammatory response in human osteoarthritic chondrocytes. Eur J Pharmacol. 2015; 756:38-42.

10. Ma Z, Piao T, Wang Y, Liu J. Astragalin inhibits IL-1betainduced inflammatory mediators production in human osteoarthritis chondrocyte by inhibiting NF-kappaB and MAPK activation. Int Immunopharmacol. 2015; 25:83-87.

11. Kong P, Chen G, Jiang A, Wang Y, Song C, Zhuang J, Xi C, Wang G, Ji Y, Yan J. Sesamin inhibits IL-1 $\beta$-stimulated inflammatory response in human osteoarthritis chondrocytes by activating Nrf2 signaling pathway. Oncotarget. 2016; 7:83720-83726. doi: 10.18632/oncotarget.13360.

12. Chen P, Xia C, Mei S, Wang J, Shan Z, Lin X, Fan S. Intra-articular delivery of sinomenium encapsulated by chitosan microspheres and photo-crosslinked GelMA hydrogel ameliorates osteoarthritis by effectively regulating autophagy. Biomaterials. 2016; 81:1-13.

13. Xia C, Chen P, Mei S, Ning L, Lei C, Wang J, Zhang J, Ma J, Fan S. Photo-crosslinked HAMA hydrogel with cordycepin encapsulated chitosan microspheres for osteoarthritis treatment. Oncotarget. 2017; 8:2835-2849. doi: 10.18632/oncotarget.13748.

14. Ma J, Ma Y, Liu X, Chen S, Liu C, Qin A, Fan S. Gambogic acid inhibits osteoclast formation and ovariectomyinduced osteoporosis by suppressing the JNK, p38 and Akt signalling pathways. Biochem J. 2015; 469:399-408.

15. Grenby TH. The use of sanguinarine in mouthwashes and toothpaste compared with some other antimicrobial agents. Br Dent J. 1995; 178:254-258.

16. Singh CK, Kaur S, George J, Nihal M, Pellitteri HM, Scarlett CO, Ahmad N. Molecular signatures of sanguinarine in human pancreatic cancer cells: a large scale label-free comparative proteomics approach. Oncotarget. 2015; 6:10335-10348. doi: 10.18632/oncotarget.3231.

17. Mackraj I, Govender T, Gathiram P. Sanguinarine. Cardiovasc Ther. 2008; 26:75-83.

18. Li H, Zhai Z, Liu G, Tang T, Lin Z, Zheng M, Qin A, Dai K. Sanguinarine inhibits osteoclast formation and bone resorption via suppressing RANKL-induced activation of NF-kappaB and ERK signaling pathways. Biochem Biophys Res Commun. 2013; 430:951-956.

19. Godowski KC. Antimicrobial action of sanguinarine. J Clin Dent. 1989; 1:96-101.

20. Mitscher LA, Drake S, Gollapudi SR, Okwute SK. A modern look at folkloric use of anti-infective agents. J Nat Prod. 1987; 50:1025-1040.

21. Li W, Li H, Mu Q, Zhang H, Yao H, Li J, Niu X. Protective effect of sanguinarine on LPS-induced endotoxic shock in mice and its effect on LPS-induced COX-2 expression and COX-2 associated PGE2 release from peritoneal macrophages. Int Immunopharmacol. 2014; 22:311-317.

22. Niu X, Fan T, Li W, Huang H, Zhang Y, Xing W. Protective effect of sanguinarine against acetic acid-induced ulcerative colitis in mice. Toxicol Appl Pharmacol. 2013; 267:256-265.

23. Ozawa M, Nishida K, Yoshida A, Saito T, Harada R, Machida T, Ozaki T. Hyaluronan suppresses mechanical stress-induced expression of catabolic enzymes by human chondrocytes via inhibition of IL-1 $\beta$ production and subsequent NF- $\kappa \mathrm{B}$ activation. Inflamm Res. 2015; 64:243-252.

24. Kato T, Miyaki S, Ishitobi H, Nakamura Y, Nakasa T, Lotz MK, Ochi M. Exosomes from IL-1 $\beta$ stimulated synovial fibroblasts induce osteoarthritic changes in articular chondrocytes. Arthritis Res Ther. 2014; 16:R163.

25. Clark IM, Parker AE. Metalloproteinases: their role in arthritis and potential as therapeutic targets. Expert Opin Ther Targets. 2003; 7:19-34.

26. Glasson SS, Askew R, Sheppard B, Carito B, Blanchet T, Ma HL, Flannery CR, Peluso D, Kanki K, Yang Z, Majumdar MK, Morris EA. Deletion of active ADAMTS5 prevents cartilage degradation in a murine model of osteoarthritis. Nature. 2005; 434:644-648.

27. Stanton H, Rogerson FM, East CJ, Golub SB, Lawlor KE, Meeker CT, Little CB, Last K, Farmer PJ, Campbell IK, Fourie AM, Fosang AJ. ADAMTS5 is the major aggrecanase in mouse cartilage in vivo and in vitro. Nature. 2005; 434:648-652.

28. Huang C, Liao G, Han J, Zhang G, Zou B. Edaravone suppresses degradation of type II collagen. Biochem Biophys Res Commun. 2016; 473:840-844.

29. Vincenti MP, Brinckerhoff CE. Transcriptional regulation of collagenase (MMP-1, MMP-13) genes in arthritis: integration of complex signaling pathways for the recruitment of gene-specific transcription factors. Arthritis Res. 2002; 4:157-164. 
30. Roman-Blas JA, Jimenez SA. NF-kappaB as a potential therapeutic target in osteoarthritis and rheumatoid arthritis. Osteoarthritis Cartilage. 2006; 14:839-848.

31. Ghosh M, Aguirre V, Wai K, Felfly H, Dietrich WD, Pearse DD. The interplay between cyclic AMP, MAPK, and NF-kappaB pathways in response to proinflammatory signals in microglia. Biomed Res Int. 2015; 2015:308461.

32. Yang S, Kim J, Ryu JH, Oh H, Chun CH, Kim BJ, Min BH, Chun JS. Hypoxia-inducible factor-2alpha is a catabolic regulator of osteoarthritic cartilage destruction. Nat Med. 2010; 16:687-693.

33. Ismail HM, Yamamoto K, Vincent TL, Nagase H, Troeberg L, Saklatvala J. Interleukin-1 acts via the JNK-2 signaling pathway to induce aggrecan degradation by human chondrocytes. Arthritis Rheumatol. 2015; 67:1826-1836.

34. Chaturvedi MM, Kumar A, Darnay BG, Chainy GB, Agarwal S, Aggarwal BB. Sanguinarine (pseudochelerythrine) is a potent inhibitor of NF-kappaB activation, IkappaBalpha phosphorylation, and degradation. J Biol Chem. 1997; 272:30129-30134.

35. Niu X, Fan T, Li W, Xing W, Huang H. The antiinflammatory effects of sanguinarine and its modulation of inflammatory mediators from peritoneal macrophages. Eur J Pharmacol. 2012; 689:262-269.

36. Gosset M, Berenbaum F, Thirion S, Jacques C. Primary culture and phenotyping of murine chondrocytes. Nat Protoc. 2008; 3:1253-1260.

37. Galois L, Etienne S, Grossin L, Watrin-Pinzano A, Cournil-Henrionnet C, Loeuille D, Netter P, Mainard D, Gillet P. Dose-response relationship for exercise on severity of experimental osteoarthritis in rats: a pilot study. Osteoarthritis Cartilage. 2004; 12:779-786.

38. Pritzker KP, Gay S, Jimenez SA, Ostergaard K, Pelletier JP, Revell PA, Salter D, van den Berg WB. Osteoarthritis cartilage histopathology: grading and staging. Osteoarthritis Cartilage. 2006; 14:13-29. 